\title{
Estimation of the level of macrophage migration inhibitory factor in patients with coronary artery disease in the presence of some risk factors
}

\begin{abstract}
Background and objective: Coronary artery disease is a chronic inflammatory disease in which many risk factors and inflammatory mediators, including macrophage migration inhibitory factor, are involved. This study aimed to estimate macrophage migration inhibitory factor level in coronary artery disease patients in regard to age, gender, and smoking.
\end{abstract}

Methods: A total of 138 coronary artery disease patients and 38 coronary artery disease free control subjects were admitted to surgical specialty hospital-cardiac center in Erbil city, Iraq between January and December 2017. Plasma macrophage migration inhibitory factor concentration was measured by enzyme linked immunosorbent assay.

Results: Patients and controls were categorized into subgroups according to age ( $<55$ and $\geq 55$ years), gender (women and men), and smoking status (smokers and non-smokers). Macrophage migration inhibitory factor level in every coronary artery disease subgroup (age, gender, and smokers) patients increased significantly compared to the same control subgroups $(P<0.05)$. Macrophage migration inhibitory factor level showed a higher level in coronary artery disease patients subgroups ( $\geq 55$ years, female, smokers) compared to their corresponding coronary artery disease subgroups ( $<55$ years, male, and non smokers). Macrophage migration inhibitory factor demonstrated a significant positive correlation with fibrinogen and high sensitivity C-reactive protein, insignificant positive correlation with age, total cholesterol, low density lipoprotein, and insignificant negative correlation with high density lipoprotein-cholesterol $(P>0.05)$.

Conclusion: This study demonstrated the diagnostic value of macrophage migration inhibitory factor elevation in coronary artery disease patients if compared with coronary artery disease free subjects, meanwhile suggesting that age, gender, and smoking had no direct role in macrophage migration inhibitory factor elevation considering their secondary minor contributions in macrophage migration inhibitory factor circulation.

Keywords: Coronary; Macrophage; Age; Gender; Smoking.

\section{Introduction}

Coronary artery disease (CAD) is a consequence of the pathological process of atherosclerosis. It affects medium and large sized arteries and characterizes by the formation of atherosclerotic plaque, which is composed of necrotic center, calcified area, and accumulation of modified lipid, inflamed endothelial cells, smooth muscle cells, leukocytes, and foam cells. ${ }^{1}$ This demonstrates the significant role of inflammatory cells and mediators in the formation, development, and progression of atherosclerotic plaques. ${ }^{2}$ Various risk factors, such as gender, smoking, obesity, hypertension, and diabetes mellitus, are also implicated in CAD development. ${ }^{3}$ The proinflammatory cytokine, macrophage migration inhibitory factor (MIF), has a critical contributing role in the progression of atherosclerotic plaques by regulating the recruitment of various inflammatory cells towards plaque lesions. ${ }^{4}$ Previous studies revealed that

${ }^{1}$ Department of Basic Sciences, College of Medicine, Hawler Medical University, Erbil, I raq.

* Correspondence: feyan.mirdan@hmu.edu.krd 
MIF up regulation is linked with macrophage adhesion, aggregation, and formation of foam cells, indicating the critical role of MIF in plaque instability and susceptibility to rupture. ${ }^{5}$ Moreover, a significant elevation of MIF level was observed in acute coronary syndrome patients compared to stable CAD patients. ${ }^{6,7}$ Besides, elevated MIF revealed a positive correlation with the degree of cardiac infarction at first admitted obtainable plasma sample, mainly denoted the valuable utility of MIF as a predictive biomarker for infarction size. ${ }^{8}$ On the other hand, it was observed that blockade of this atherogenic factor might lead to plaque stabilization and regression, recognizing MIF from other cytokines involved in the pathology of atherosclerosis, and determining why the possibility of therapeutically targeting MIF should be taken into consideration. ${ }^{9}$ This study aimed to estimate the level of MIF in CAD patients compared to subjects confirmed to be free from CAD in association with some risk factors such as age, gender, and smoking.

\section{Methods}

A case-control study was enrolled 138 CAD patients and 38 control individuals who were admitted to surgical specialty hospital -cardiac center in Erbil City, Iraq between January and December 2017. Coronary angiography (COA) was done for all participants through the right femoral artery, and percutaneous coronary intervention $(\mathrm{PCl})$ was achieved only for those patients who showed significant or new critical arterial obstructions. Of 138 CAD patients, 100 patients had myocardial infarction (MI) diagnosed according to world health organization criteria, ${ }^{10}$ and 38 patients had stable angina pectoris (SAP) who confirmed by COA to have critical lesions, and had no recent change in the incidence, and severity of angina chest pain. The number of affected arteries was determined according to the results of COA. The control group included patients admitted for chest pain that was not associated with cardiac reasons, and they confirmed to have normal COA. Patients with any evidence of autoimmune, inflammatory, or malignant diseases were excluded from the study. Cases with post $\mathrm{MI}$, heart failure, or other related heart manifestations and those with stroke, recent surgery were also excluded from the study. The study protocol was approved by the research ethics committee in the College of Medicine, Hawler Medical University. Baseline information was obtained through a direct personal interview with all participants using a well prepared questionnaire format. Body mass index was calculated depending on the standard equation (weight $\mathrm{Kg} /$ height $\mathrm{m}^{2}$ ). Approximately $8 \mathrm{ml}$ of the venous blood sample was obtained from each patient and control subjects once they were admitted to the cardiac center and before angiography. The obtained serum and plasma were kept in many aliquot tubes and stored at $-80^{\circ} \mathrm{C}$ for further investigations. Plasma MIF concentration was measured by sandwich ELISA kits (Mybiosource, USA). Fibrinogen concentration was determined using Clauss method and Fibri-prestautomate, (DiagnosticaStago, France) kit. Particle enhanced immunoturbidimetric technique was used to estimate serum hsCRP using cobs 111 (Roche Diagnostics $\mathrm{GmbH}$ ). Based on the manufacture's instructions, the lipid profile was estimated using cobs 111 (Roche Diagnostics $\mathrm{GmbH}$ ).

\section{Statistical analysis:}

Data were analyzed using the statistical package for the social sciences (version 23.0). Comparison between two independent variables was achieved using t-test and expressed as mean \pm standard error (SE). Correlations between data were analyzed by the Pearson correlation coefficient test. A $P$ value of $<0.05$ was expressed as statistically significant. 


\section{Results}

Table 1 displays the baseline information of CAD patients. Patient age ranged between 35-85 years with a mean of $58.39 \pm 1.26$ years. The mean value of BMl of $28.75 \pm 0.55$ indicated the overweight tendency of the patients. Higher proportions of the cases were male, illiterate, married, and working in the private sector $(69.57 \%, 46.38 \%, 82.61 \%$, and $70.29 \%$, respectively). Patients were mostly affected by three diseased arteries $(59.42 \%)$. Aspirin and statin were used in the majority of the cases $(94.20 \%$ and $78.26 \%$, respectively). More details are illustrated in Table 1.

Table 1: Baseline information of CAD patients.

\begin{tabular}{|c|c|}
\hline Variables & CAD patients \\
\hline Age (years) & $58.39 \pm 1.26$ \\
\hline Age range & $(35-85)$ years \\
\hline BMI $\left(\mathrm{kg} / \mathrm{m}^{2}\right)$ & $28.75 \pm 0.55$ \\
\hline \multicolumn{2}{|l|}{ Lipid profile and ratios } \\
\hline $\mathrm{TC}(\mathrm{mg} / \mathrm{dl})$ & $182.92 \pm 9.28$ \\
\hline HDL-C (mg/dl) & $37.23 \pm 1.11$ \\
\hline LDL-C (mg/dl) & $115.62 \pm 4.10$ \\
\hline Triglycerides (mg/dl) & $156.72 \pm 12.80$ \\
\hline Non-HDL (mg/dl) & $145.69 \pm 9.23$ \\
\hline $\mathrm{TC} / \mathrm{HDL}$ ratio & $5.15 \pm 0.33$ \\
\hline LDL/HDL ratio & $3.23 \pm 0.13$ \\
\hline \multicolumn{2}{|c|}{ Inflammatory biomarkers } \\
\hline MIF (ng/ml) & $39.64 \pm 2.67$ \\
\hline Fibrinogen (mg/dl) & $448.09 \pm 17.59$ \\
\hline $\mathrm{hsCRP}(\mathrm{mg} / \mathrm{L})$ & $8.95 \pm 1.38$ \\
\hline \multicolumn{2}{|l|}{ No $(\%)$} \\
\hline Male & $96(69.57)$ \\
\hline smokers & $95(68.84)$ \\
\hline Myocardial infarction & $100(72.46)$ \\
\hline Stable angina pectoris & $38(27.54)$ \\
\hline \multicolumn{2}{|l|}{ Education Levels } \\
\hline Illiterate & $64(46.38)$ \\
\hline Primary + secondary & $48(34.78)$ \\
\hline High School and above & $26(18.84)$ \\
\hline \multicolumn{2}{|l|}{ Marital status } \\
\hline Single & $5(3.62)$ \\
\hline Married & $114(82.61)$ \\
\hline Widowed / divorce & $19(13.77)$ \\
\hline \multicolumn{2}{|l|}{ Occupation } \\
\hline Public sector & $26(18.84)$ \\
\hline Private sector & $97(70.29)$ \\
\hline Retired & $15(10.87)$ \\
\hline \multicolumn{2}{|l|}{ Diseased vessels } \\
\hline 1 vessel & $31(22.46)$ \\
\hline 2 vessels & $25(18.12)$ \\
\hline 3 vessels & $82(59.42)$ \\
\hline \multicolumn{2}{|l|}{ Medications } \\
\hline Aspirin & $130(94.20)$ \\
\hline Statin & $108(78.26)$ \\
\hline
\end{tabular}

Data are presented mean \pm SE and as number (\%). Body mass index: BMl; Total cholesterol:

TC; MIF: macrophage migration inhibitory factor; hsCRP: high sensitivity $C$ reactive protein;

DHL-C: high density lipoprotein-cholesterol;LDL-C; LDL: low density lipoprotein-cholesterol. 
In Table 2, patients and control group were divided according to age $(<55$ and $\geq 55$ years). MIF level in patients with both age subgroups $<55$ and $\geq 55$ years differed significantly compared to control subgroups $(P<0.05)$. CAD patients with age subgroup $\geq 55$ years had higher MIF level than CAD patients with age subgroup $<55$ years. Fibrinogen and hsCRP levels in CAD subgroups $<55$ years differed significantly compared to control with the same age subgroup $(P<0.05)$. No statistically significant difference was observed for both biomarkers between $\mathrm{CAD}$ and controls with age subgroup $\geq 55$ years $(P>0.05)$. Lipid profile and their ratios showed higher levels in the youngest CAD subgroup compared to the oldest one. A significant difference was observed between CAD and control subjects with age subgroups $<55$ years for triglyceride, HDL-C, LDL-C, $\mathrm{TC} / \mathrm{HDL}$, and LDL/HDL $(P<0.05)$. Similar significant results were observed for HDL-C and LDL/HDL, LDL/HDL within age subgroups $\geq 55$ years $(P<0.05)$.

Table 2: Comparison of MIF level and other inflammatory biomarkers, lipid profile between CAD patients and controls in regard to age subgroups $(<55$, and $\geq 55$ ).

\begin{tabular}{|c|c|c|c|c|c|c|}
\hline Variables & $\begin{array}{c}\text { CAD } \\
\text { patients } \\
\\
<55 \\
(n=59)\end{array}$ & $\begin{array}{l}\text { Controls } \\
\qquad \begin{array}{c}<55 \\
(n=19)\end{array}\end{array}$ & $P$ value & $\begin{array}{l}\text { CAD patients } \\
\begin{array}{c}\geq 55 \\
(n=79)\end{array}\end{array}$ & $\begin{array}{l}\text { Controls } \\
\qquad \begin{array}{c}\geq 55 \\
(n=19)\end{array}\end{array}$ & $P$ value \\
\hline \multicolumn{7}{|c|}{ Inflammatory biomarkers } \\
\hline MIF (ng/ml) & $38.17 \pm 4.27$ & $20.58 \pm 4.23$ & 0.025 & $40.78 \pm 3.43$ & $21.43 \pm 6.06$ & 0.021 \\
\hline Fibrinogen (mg/dl) & $419.37 \pm 26.81$ & $303.30 \pm 29.54$ & 0.020 & $470.18 \pm 22.98$ & $409.36 \pm 33.17$ & 0.259 \\
\hline hsCRP (mg/L) & $9.01 \pm 2.26$ & $1.47 \pm 0.34$ & 0.042 & $8.91 \pm 1.75$ & $2.70 \pm 0.49$ & 0.119 \\
\hline \multicolumn{7}{|c|}{ Lipid profile and lipid ratios } \\
\hline $\mathrm{TC}(\mathrm{mg} / \mathrm{dl})$ & $201.04 \pm 19.23$ & $158.16 \pm 16.30$ & 0.207 & $168.98 \pm 6.61$ & $172.28 \pm 15.92$ & 0.840 \\
\hline $\begin{array}{l}\text { Ttiglyceride (mg/ } \\
\text { dl) }\end{array}$ & $174.13 \pm 19.03$ & $101.57 \pm 12.63$ & 0.032 & $143.33 \pm 17.19$ & $148.07 \pm 15.21$ & 0.903 \\
\hline HDL-C (mg/dl) & $37.28 \pm 1.92$ & $53.08 \pm 2.85$ & 0.001 & $37.19 \pm 1.33$ & $45.06 \pm 3.97$ & 0.026 \\
\hline LDL-C (mg/dl) & $118.38 \pm 6.00$ & $87.94 \pm 9.44$ & 0.011 & $113.50 \pm 5.64$ & $100.08 \pm 13.54$ & 0.338 \\
\hline Non-HDL (mg/dl) & $163.75 \pm 19.41$ & $105.07 \pm 16.93$ & 0.091 & $131.79 \pm 6.10$ & $127.22 \pm 16.17$ & 0.766 \\
\hline $\mathrm{TC} / \mathrm{HDL}$ & $5.76 \pm 0.69$ & $3.08 \pm 0.35$ & 0.029 & $4.69 \pm 0.21$ & $4.03 \pm 0.43$ & 0.210 \\
\hline LDL/HDL & $3.32 \pm 0.20$ & $1.72 \pm 0.21$ & 0.001 & $3.16 \pm 0.18$ & $2.33 \pm 0.30$ & 0.044 \\
\hline BMI $\left(\mathrm{kg} / \mathrm{m}^{2}\right)$ & $28.75 \pm 0.81$ & $25.10 \pm 0.54$ & 0.013 & $28.76 \pm 0.76$ & $26.93 \pm 0.58$ & 0.293 \\
\hline
\end{tabular}


MIF level and other inflammatory biomarkers were compared according to gender differences between CAD patients and control subjects. Women revealed a significantly higher mean value of MIF, fibrinogen, and hsCRP compared to women controls $(P<0.05)$. However, men subgroups showed a significant difference only for MIF and hsCRP $(P<0.05)$. CAD women revealed higher MIF, fibrinogen, and hsCRP levels compared to CAD men. Regarding lipid profile and its ratios, a lower level of HDL-C was observed in CAD men. HDL-C, LDL- and lipid ratios differed significantly between women subgroups $(P<0.05)$, Table 3.

Table 3: Comparison of MIF level and other parameters between CAD patients and control group in regard to gender difference.

\begin{tabular}{|c|c|c|c|c|c|c|}
\hline \multirow{2}{*}{ Variables } & & & \multirow[b]{2}{*}{$P$ value } & \multirow{2}{*}{\multicolumn{2}{|c|}{$\begin{array}{l}\text { Control } \\
\text { Male } \\
(n=22)\end{array}$}} & \multirow[b]{2}{*}{$P$ value } \\
\hline & $\begin{array}{l}\text { Female } \\
(n=42)\end{array}$ & $\begin{array}{l}\text { Female } \\
(n=16)\end{array}$ & & & & \\
\hline BMI $\left(\mathrm{kg} / \mathrm{m}^{2}\right)$ & $30.68 \pm 0.93$ & $25.75 \pm 0.79$ & 0.005 & $27.90 \pm 0.65$ & $25.95 \pm 0.54$ & 0.166 \\
\hline Age (years) & $60.90 \pm 2.25$ & $52.12 \pm 3.49$ & 0.048 & $57.29 \pm 1.51$ & $52.63 \pm 2.47$ & 0.173 \\
\hline \multicolumn{7}{|c|}{ Inflammatory Markers } \\
\hline MIF (ng/ml) & $41.91 \pm 5.58$ & $20.84 \pm 3.38$ & 0.006 & $38.65 \pm 2.99$ & $21.01 \pm 5.55$ & 0.012 \\
\hline Fibrinogen (mg/dl) & $512.30 \pm 27.71$ & $350.07 \pm 42.05$ & 0.004 & $419.99 \pm 21.10$ & $346.41 \pm 31.71$ & 0.121 \\
\hline hsCRP (mg/L) & $12.47 \pm 3.47$ & $2.31 \pm 0.47$ & 0.043 & $7.40 \pm 1.25$ & $1.74 \pm 0.42$ & 0.036 \\
\hline \multicolumn{7}{|c|}{ Lipid profile and lipid ratios } \\
\hline $\mathrm{TC}(\mathrm{mg} / \mathrm{dl})$ & $182.72 \pm 10.40$ & $163.90 \pm 13.54$ & 0.328 & $183.01 \pm 12.60$ & $164.25 \pm 17.60$ & 0.502 \\
\hline $\begin{array}{l}\text { Triglyceride (mg/ } \\
\text { dl) }\end{array}$ & $163.96 \pm 17.95$ & $130.16 \pm 19.49$ & 0.295 & $153.55 \pm 16.74$ & $114.60 \pm 12.83$ & 0.280 \\
\hline HDL-C (mg/dl) & $39.15 \pm 2.28$ & $51.22 \pm 4.81$ & 0.017 & $36.39 \pm 1.25$ & $48.60 \pm 2.60$ & 0.001 \\
\hline LDL-C (mg/dl) & $120.14 \pm 8.17$ & $90.11 \pm 5.93$ & 0.039 & $113.64 \pm 4.71$ & $95.19 \pm 13.02$ & 0.118 \\
\hline Non-HDL (mg/dl) & $143.56 \pm 9.84$ & $112.68 \pm 15.81$ & 0.110 & $146.62 \pm 12.62$ & $115.65 \pm 17.69$ & 0.270 \\
\hline $\mathrm{TC} / \mathrm{HDL}$ & $4.80 \pm 0.30$ & $3.48 \pm 0.47$ & 0.031 & $5.31 \pm 0.45$ & $3.48 \pm 0.38$ & 0.065 \\
\hline LDL/HDL & $3.14 \pm 0.22$ & $1.91 \pm 0.25$ & 0.005 & $3.27 \pm 0.17$ & $2.02 \pm 0.27$ & 0.002 \\
\hline
\end{tabular}

Values are presented as mean \pm SE using $t$ test, $P$ values $<0.05$ considered statistically significant. 
Table 4 demonstrates a comparison of MIF and other variables between smokers and non smoker in CAD and control subjects. Smoker subgroups were showed lower BMI, and the difference was observed between non smokers subgroups $(P<0.05)$. Smoker CAD showed a higher MIF level than other study subgroups, with a statistically significant difference compared to smoker control $(P<0.05)$. Similar results were observed concerning fibrinogen and hsCRP. Additionally, MIF in non smokers CAD was significantly higher than its corresponding control group $(P<0.05)$. Although TC, triglyceride, and non HDL levels were higher in smokers $C A D$, the difference was insignificant compared to smokers controls $(P>0.05)$. Conversely, the mean concentration of HDL-C level showed a lower value in smoker CAD, and the difference was statistically significant compared to smoker control $(P<0.05)$.

Table 4: Comparison of MIF and other variables between cad and control group according to smoking status.

\begin{tabular}{|c|c|c|c|c|c|c|}
\hline & CAD & Control & & CAD & Control & \\
\hline Variables & $\begin{array}{c}\text { Non- } \\
\text { Smokers } \\
(n=43)\end{array}$ & $\begin{array}{c}\text { Non- } \\
\text { Smokers } \\
(n=22)\end{array}$ & $P$ value & $\begin{array}{c}\text { Smokers } \\
(n=95)\end{array}$ & $\begin{array}{c}\text { Smokers } \\
(n=16)\end{array}$ & $P$ value \\
\hline Age (years) & $59.04 \pm 1.64$ & $50.81 \pm 2.72$ & 0.01 & $58.08 \pm 1.69$ & $54.62 \pm 2.90$ & 0.424 \\
\hline BMI $\left(\mathrm{kg} / \mathrm{m}^{2}\right)$ & $30.50 \pm 0.99$ & $26.02 \pm 0.67$ & 0.005 & $27.93 \pm 0.63$ & $25.65 \pm 0.54$ & 0.153 \\
\hline \multicolumn{7}{|c|}{ Inflammatory Markers } \\
\hline MIF (ng/ml) & $37.69 \pm 5.08$ & $18.62 \pm 3.27$ & 0.017 & $40.56 \pm 3.14$ & $24.13 \pm 6.95$ & 0.044 \\
\hline Fibrinogen (mg/dl) & $445.08 \pm 31.17$ & $355.66 \pm 41.73$ & 0.102 & $449.50 \pm 21.53$ & $337.36 \pm 17.24$ & 0.039 \\
\hline hsCRP (mg/L) & $8.30 \pm 2.41$ & $2.45 \pm 0.37$ & 0.101 & $9.25 \pm 1.70$ & $1.34 \pm 0.47$ & 0.043 \\
\hline \multicolumn{7}{|c|}{ Lipid profile and lipid ratios } \\
\hline $\mathrm{TC}(\mathrm{mg} / \mathrm{dl})$ & $180.30 \pm 10.00$ & $175.58 \pm 18.27$ & 0.806 & $184.15 \pm 12.86$ & $148.33 \pm 8.66$ & 0.262 \\
\hline Triglyceride (mg/dl) & $149.13 \pm 16.12$ & $119.35 \pm 15.79$ & 0.251 & $160.27 \pm 17.30$ & $123.63 \pm 15.23$ & 0.395 \\
\hline HDL-C (mg/dl) & $39.06 \pm 2.37$ & $52.56 \pm 3.31$ & 0.002 & $36.37 \pm 1.20$ & $45.78 \pm 3.41$ & 0.005 \\
\hline LDL-C (mg/dl) & $122.36 \pm 8.20$ & $99.62 \pm 12.61$ & 0.130 & $112.46 \pm 4.62$ & $84.02 \pm 6.14$ & 0.017 \\
\hline Non-HDL (mg/dl) & $141.23 \pm 9.64$ & $123.01 \pm 19.01$ & 0.347 & $147.77 \pm 12.84$ & $102.55 \pm 10.99$ & 0.159 \\
\hline $\mathrm{TC} / \mathrm{HDL}$ & $4.80 \pm 0.31$ & $3.51 \pm 0.41$ & 0.022 & $5.32 \pm 0.46$ & $3.43 \pm 0.42$ & 0.105 \\
\hline LDL/HDL & $3.24 \pm 0.23$ & $1.99 \pm 0.26$ & 0.003 & $3.23 \pm 0.17$ & $1.97 \pm 0.28$ & 0.005 \\
\hline
\end{tabular}

Values are presented as mean \pm SE using t-test, $P$ values $<0.05$ considered statistically significant. 
Pearson correlation analysis showed significant positive correlation between MIF and fibrinogen $(r=0.343 ; P=0.004)$. Similar results was observed regarding MIF and hsCRP ( $r=0.390, P=0.001)$. Fibrinogen and hsCRP also correlated significantly $(r=0.245 ; \quad P=0.042)$. MIF correlated positively but insignificantly with age $(r=0.065 ; \quad P=0.596), \quad$ TC $\quad(r=0.150 ;$

$P=0.219), \quad$ triglyceride $\quad(r=0.050$;

$P=0.683)$, and LDL-C $(r=0.160$;

$P=0.189)$. Meanwhile, HDL-C showed negative insignificant correlation with MIF, fibrinogen, and hsCRP ( $\mathrm{r}=-0.12 ; P=0.923$, $\mathrm{r}=-0.110 ; P=0.368, \mathrm{r}=-0.060 ; P=0.624)$ respectively, Table 5 .

Table 5: Correlation of MIF with other parameters in cad patients.

\begin{tabular}{|c|c|c|c|c|}
\hline \multicolumn{2}{|c|}{ Parameters } & MIF & Fibrinogen & hsCRP \\
\hline MIF & $\begin{array}{l}r \\
P\end{array}$ & - & - & - \\
\hline Fibrinogen & $\begin{array}{l}r \\
p\end{array}$ & $\begin{array}{c}0.343^{* *} \\
0.004\end{array}$ & - & - \\
\hline hsCRP & $\begin{array}{l}r \\
p\end{array}$ & $\begin{array}{c}0.390^{* *} \\
0.001\end{array}$ & $\begin{array}{c}0.245^{*} \\
0.042\end{array}$ & - \\
\hline Age & $\begin{array}{l}r \\
p\end{array}$ & $\begin{array}{l}0.065 \\
0.596\end{array}$ & $\begin{array}{c}0.279^{*} \\
0.020\end{array}$ & $\begin{array}{l}0.063 \\
0.610\end{array}$ \\
\hline $\mathrm{TC}$ & $\begin{array}{l}r \\
p\end{array}$ & $\begin{array}{l}0.150 \\
0.219\end{array}$ & $\begin{array}{l}0.215 \\
0.076\end{array}$ & $\begin{array}{c}0.276^{*} \\
0.022\end{array}$ \\
\hline Triglyceride & $\begin{array}{l}r \\
p\end{array}$ & $\begin{array}{l}0.050 \\
0.683\end{array}$ & $\begin{array}{l}0.019 \\
0.875\end{array}$ & $\begin{array}{l}0.105 \\
0.390\end{array}$ \\
\hline HDL-C & $\begin{array}{l}r \\
p\end{array}$ & $\begin{array}{l}-0.12 \\
0.923\end{array}$ & $\begin{array}{c}-0.110 \\
0.368\end{array}$ & $\begin{array}{c}-0.060 \\
0.624\end{array}$ \\
\hline LDL-C & $\begin{array}{l}r \\
p\end{array}$ & $\begin{array}{l}0.160 \\
0.189\end{array}$ & $\begin{array}{l}0.220 \\
0.066\end{array}$ & $\begin{array}{l}0.232 \\
0.055\end{array}$ \\
\hline
\end{tabular}




\section{Discussion}

In the current study, we aimed to estimate the level of MIF in CAD patients compared to control subjects in association with some risk factors (age, gender, and smoking status). According to our best information studies, the estimated MIF level in CAD patients regarding the aforementioned risk factors is limited. Patients in the present study were at the end of their fifties. Similar results were observed by previous Iraqi studies. ${ }^{11,12}$ On the contrary, the age average of the current study was lower than that reported by Turkish and Iranian studies, ${ }^{13,14}$ demonstrating that Iraqi individuals were found to develop CAD at a younger age if compared with individuals in these two neighboring countries. The mean value of $\mathrm{BMl}$ for the patients in the present study (28.75) was higher than that reported by Akcilar et al. (27.0), ${ }^{13}$ but lower than that recorded by Albarzani(30.19). ${ }^{12}$ The current lifestyle, which is associated with high fat intake and low physical activity, encourages atherosclerosis. Obesity and increasing fat consumption were found to be linked with longstanding inflammation in both arteries and adipose tissues. $^{15}$ Overall, the MIF level was increased significantly in CAD patients with both age subgroups ( $<55$ and $\geq 55$ years) compared to control subgroups. Previous studies also reported that plasma MIF level in CAD patients was higher than non-CAD subjects. ${ }^{16,17}$ Elevation of MIF level could be explained by the overexpression of this cytokine in endothelial cells and macrophages in human atherosclerotic plaques, mainly those with progressive stages. These cells express MIF as a response to oxidized LDL. ${ }^{18}$ Additionally, the theroprogressive feature of MIF has been confirmed by numerous mouse studies, possibly attributed to its pro-inflammatory action at atherosclerotic regions. For instance, activation of endothelial cells, recruitment of monocytes, the formation of macrophage and foam cells, and destabilization of extracellular environment. ${ }^{18} \mathrm{~A}$ slight elevation of MIF level was observed in CAD patients with age subgroup $\geq 55$ years compared to those patients with age subgroup $<55$ years. This may suggest that age has unlikely contributed significantly to the circulated MIF or may have a minor role in MIF elevation, especially MIF revealed insignificant, weak positive correlation with age in the current study. Considerably, other factors may affect the MIF level in both ages of CAD subgroups. For example, hypoxia and ischemia are two medical conditions linked with $\mathrm{MI}$ and other complicated manifestations of CAD. MIF has been found to release by immune cells and cardiac tissue and exhibited upregulation at the time of hypoxia as well ischemia, a process mediated by hypoxia inducible factor- $1 \alpha{ }^{19}$ Moreover, MIF overexpression in cardiomyocytes was found to be correlated positively with hypoxias degrees. ${ }^{20}$ On the other hand, it should be taken into consideration that the majority of CAD patients in the current study were followed a particular medical regimen, and the effect of some drugs on inflammation cannot be ignored. For example, aspirin and statin both possess anti-inflammatory properties that affect plaque formation. ${ }^{21,22}$ As a consequence of their anti-inflammatory action, levels of MIF, fibrinogen, and hsCRP could be influenced. What is more, drugs doses were a case severity dependent, which was decided by a specialist cardiologist. In their study, Müller et al. reported that CAD patients who had higher MIF level were older than those who had lower MIF level, and the difference was significant. ${ }^{7}$ The current study demonstrated that both CAD women and men had significantly higher MIF concentration compared to control women and men. Moreover, CAD women were older and had significantly higher BMI, fibrinogen, hsCRP, LDL-C, and lipid ratios compared to control women. Additionally, CAD women demonstrated an increased mean value of age, BMI, inflammatory markers, triglyceride, HDL-C, and LDL-C compared to CAD men. These 
findings are in accordance with previously published studies. ${ }^{23}$ The higher MIF level in CAD women compared to CAD men is related to some genetic and hormonal variation between both genders. A significant association between MIF haplotype (C-G-C-T) and increased the risk for CAD development in women has been previously reported. However, such an association was not found in men. Moreover, this haplotype was found to contain MIF single nucleotide polymorphism (rs755622C), ${ }^{24}$ which has been found to associate with CAD susceptibility. ${ }^{25,26}$ In addition to genetic impact, the disparity between genders could be a reflection of sex hormones' effect on MIF at the transcriptional phase. For instance, in both human and mouse macrophages and monocytes, estrogen was found to regulate the production of MIF through nuclear factor $\mathrm{kB}$, an essential transcriptional regulator factor. ${ }^{27}$ Moreover, older women were more affected by CAD, and this may secondary associated with postmenopausal status, which reveals the impact of estrogen and other hormones of the female reproductive system in CAD incidence. $^{28}$ The present study revealed higher MIF level and other inflammatory markers in smoker CAD patients compared to other study groups, with a significant difference compared to smoker controls. Furthermore, smoker CADs were found to have less BMI and HDL-C, but higher TC, triglyceride, non -HDL compared to non smokers CAD. A previous study showed that tobacco use was insignificantly more in CAD patients who had higher MIF level compared to those who had lower MIF level. ${ }^{7}$ In general, smoking by the action of its essential constituents, carbon monoxide and nicotine, can lead to excess production of oxidative stress, endothelial destruction, and impairment. Smoking is correlated with elevation of TC, and triglyceride, and decreasing HDL-C levels. Smoking is recognized as an important risk factor for atherosclerosis and cardiovascular disease by enhancing intravascular inflammatory reactions..$^{29}$ In agreement with our finding, previous studies also reported a positive correlation between MIF and hsCRP, TC, triglyceride, and an inverse correlation with HDL-C. ${ }^{7,23}$

\section{Conclusion}

Our results signify the diagnostic value of elevated MIF level in CAD patients in comparison to CAD free subjects, meanwhile tends to exclude the direct effect of age, gender, and smoking as a primary cause for MIF elevation in CAD patients, and may suggest their secondary minor effects in MIF circulation. Further studies are required to support our findings.

\section{Competing interests}

The authors declare no competing interests.

\section{References}

1. Galkina E, Ley K. Immune and Inflammatory Mechanisms of Atherosclerosis. Annu Rev Immuno 2009; 27:165-97.

2. Ganguli D, Das N, Saha I, Sanapala KR, Chaudhuri D, Ghosh S, et al. Association between inflammatory markers and cardiovascular risk factors in women from Kolkata, W.B, India. Arq Bras Cardiol 2011; 96(1):38-46.

3. El-Moselhy EA, Mohammed AS, Abd El-Aziz A, Sadek I, Hagrass SA, Farag GAS. Coronary artery disease among elderly Egyptian patients: I. Socio-demographic, lifestyle, psychosocial, medical, and biochemical risk factors. Am J Gerentol Geriatr 2018; 1(2):1006.

4. Bernhagen J, Krohn R, Lue H, Gregory JL, Zernecke A, Koenen RR, et al. MIF is a noncognate ligand of CXC chemokine receptors in inflammatory and atherogenic cell recruitment, Nat Med 2007; 13(5):587-96.

5. Schober A, Bernhagen J, Thiele M, Zeiffer U, Knarren S, Roller $\mathrm{M}$, et al. Stabilization of atherosclerotic plaques by blockade of macrophage migration inhibitory factor after vascular injury in apolipoprotein E-deficient. Circulation 2004; 109(3):380-5.

6. Müller II, Müller KA, Karathanos A, Schönleber H, Rath D, Vogel S, et al. Impact of counterbalance between macrophage migration inhibitory factor and its inhibitor Gremlin-1 in patients with coronary artery disease. Atherosclerosis 2014; 237(2):426-32.

7. Müller II, Müller KA, Schönleber H, Karathanos A, 
Schneider M, Jorbenadze R, et al. Macrophage migration inhibitory factor is enhanced in acute coronary syndromes and is associated with the inflammatory response. PloS One 2012; 7(6):e38376.

8. Chan W, White DA, Wang XY, Bai RF, Liu Y, Yu $H Y$, et al. Macrophage migration inhibitory factor for the early prediction of infarct size. J Am Heart Assoc 2013; 2(5):e000226.

9. Zernecke A, Bernhagen J, Weber C. Macrophage migration inhibitory factor in cardiovascular disease. Circulation 2008; 117(12):1594-602.

10. Mendis S, Thygesen K, Kuulasmaa K, Giampaoli $\mathrm{S}$, Mahonen M, Blackett KN, et al. World Health Organization definition of myocardial infarction: 2008-09 revision. Int J Epidemiol 2011; 40(1):139 $-46$.

11. Ismael MK, Al-haleem MR, Salman RS. Evaluation of anti-Helicobacter pylori antibodies in a group of iraqi patients with atherosclerosis and coronary artery disease. Iraqi Journal of Science 2015; 56(1):81-8.

12. Albarzani MA. Angiographic profile in diabetic and non-diabetic patients with coronary artery disease in the Cardiac Specialty HospitalCardiac Center, Erbil, Iraq, Zanco Journal of Medical Sciences 2017; 21(2):1701-7.

13. Akcılar R, Yümün $G$, Bayat $Z$, Donbaloğlu $O$, Erselcan K, Ece E, et al. APJ receptor A445C gene polymorphism in Turkish patients with coronary artery disease. Int J Clin Exp Med 2015; 8(10):18793-9.

14. Razban MM, Eslami M, Bagherzadeh A. The relationship between serum levels of hs-CRP and coronary lesion severity. Clujul Med 2016; 89(3):322-6.

15. vanDiepen JA, Berbée JF, Havekes LM, Rensen PC. Interactions between inflammation and lipid metabolism_ relevance for efficacy of anti-inflammatory drugs in the treatment of atherosclerosis. Atherosclerosis 2013; 228(2):306 $-15$.

16. Hao Y, Yi SL, Zhong JQ. Serum macrophage migration inhibitory factor levels are associated with angiographically complex coronary lesions in patients with coronary artery disease. Genet Test Mol Biomarkers 2015; 19(10):556-60.

17. Qian L, Wang XY, Thapa S, Tao LY, Wu SZ, Luo GJ, et al. Macrophage migration inhibitory factor promoter polymorphisms (-794 CATT5-8): Relationship with soluble MIF levels in coronary atherosclerotic disease subjects. BMC Cardiovasc Disord 2017;17(1):144.

18. Noels H, Bernhagen J, Weber C. Macrophage migration inhibitory factor_a noncanonical chemokine important in atherosclerosis. Trends Cardiovasc Med 2009; 19(3):76-86.

19. Simons D, Grieb G, Hristov M, Pallua, N, Weber C, Bernhagen J, et al. Hypoxia-induced endothelial secretion of macrophage migration inhibitory factor and role in endothelial progenitor cell recruitment. J Cell Mol Med 2011; 15(3):668 -78 .

20. Jian Z, Li JB, Ma RY, Chen L, Zhong QJ, Wang XF, et al. Increase of macrophage migration inhibitory factor (MIF) expression in cardiomyocytes during chronic hypoxia. Clin Chim Acta 2009; 405(1-2):132-8.

21. Redondo S, Santos-Gallego CG, Ganado P, García M, Rico L, Del Rio M, et al. Acetylsalicylic acid inhibits cell proliferation by involving transforming growth factor- $\beta$. Circulation 2003; 107(4):626-9.

22. Diamantis E, Kyriakos G, Quiles-Sanchez LV, Farmaki $\mathrm{P}$, Troupis $\mathrm{T}$. The anti-inflammatory effects of statins on coronary artery disease: An updated review of the literature. Curr Cardiol Rev 2017; 13(3):209-16.

23. Boekholdt SM, Peters RJ, Day NE, Luben R, Bingham SA, Wareham NJ, et al. Macrophage migration inhibitory factor and the risk of myocardial infarction or death due to coronary artery disease in adults without prior myocardial infarction or stroke: The EPIC-Norfolk prospective population study. Am J Med 2004; 117(6):390-7.

24. Herder C, Illig T, Baumert J, Müller M, Klopp N, Khuseyinova $\mathrm{N}$, et al. Macrophage migration inhibitory factor (MIF) and risk for coronary heart disease: Results from the MONICA/KORA Augsburg case-cohort study, 1984-2002. Atherosclerosis 2008; 200(2):380-8.

25. Ji K, Wang X, Li J, Lu Q, Wang G, Xue Y, et al. Macrophage migration inhibitory factor polymorphism is associated with susceptibility to inflammatory coronary heart disease. Bio Med Research International 2015; 2015:315174.

26. Luo JY, Xu R, Li XM, Zhou Y, Zhao Q, Liu F, et al. MIF gene polymorphism rs755622 is associated with coronary artery disease and severity of coronary lesions in a Chinese Kazakh population: A case-control study. Medicine (Baltimore) 2016; 95(4):e2617.

27. Hardman MJ, Waite A, Zeef L, Burow M, Nakayama T, Ashcroft GS. Macrophage migration inhibitory factor: A central regulator of wound healing. Am J Pathol 2005; 167(6):156174.

28. Pathak LA, Shirodkar S, Ruparelia R, Rajebahadur J. Coronary artery disease in women. Indian Heart J 2017; 69(4):532-8.

29. Papathanasiou G, Mamali A, Papafloratos S, Zerva E. Effects of smoking on cardiovascular function: The role of nicotine and carbon monoxide. Health Science Journal 2014; 8(2):274-90. 